\section{RSP}

http://www.rsp.fsp.usp.br/
Revista de Saúde Pública

\title{
Public-private settlement and hospital mortality per sources of payment
}

Juliana Pires Machado', Mônica Martins", luri da Costa Leite"II

' Diretoria de Desenvolvimento Setorial. Agência Nacional de Saúde Suplementar. Rio de Janeiro, RJ, Brasil

" Departamento de Administração e Planejamento em Saúde. Escola Nacional de Saúde Pública. Fundação Oswaldo Cruz. Rio de Janeiro, RJ, Brasil

II' Departamento de Epidemiologia e Métodos Quantitativos em Saúde. Escola Nacional de Saúde Pública. Fundação Oswaldo Cruz. Rio de Janeiro, RJ, Brasil

\section{ABSTRACT}

OBJECTIVE: To analyze if the adjusted hospital mortality varies according to source of payment of hospital admissions, legal nature, and financing settlement of hospitals.

METHODS: Cros-ssectional study with information source in administrative databases. Specific hospital admission reasons were selected considering the volume of hospital admissions and the list of quality indicators proposed by the North-American Agency for Healthcare Research and Quality (AHRQ). Were analyzed 852,864 hospital admissions of adults, occurred in 789 hospitals between 2008 and 2010, in Sao Paulo and Rio Grande do Sul, applying multilevel logistic regression.

RESULTS: At hospital admission level, showed higher chances of death male patients in more advanced age groups, with comorbidity, who used intensive care unit, and had the Brazilian Unified Health System as source of payment. At the level of hospitals, in those located in the mean of the distribution, the adjusted probability of death in hospital admissions financed by plan or private was $5.0 \%$, against 9.0\% when reimbursed by the Brazilian Unified Health System. This probability increased in hospital admissions financed by the Brazilian Unified Health System in hospitals to two standard deviations above the mean, reaching $29.0 \%$.

CONCLUSIONS: In addition to structural characteristics of the hospitals and the profile of the patients, interventions aimed at improving care should also consider the coverage of the population by health plans, the network shared between beneficiaries of plans and users of the Brazilian Unified Health System, the standard of care to the various sources of payment by hospitals and, most importantly, how these factors influence the clinical performance.

DESCRIPTORS: Hospital Mortality. Private Health Care Coverage. Public-Private Sector Partnerships. Unified Health System. Outcome and Process Assessment (Health Care). and source are credited.

Correspondence:

DIDES/ANS

Av. Augusto Severo, $8410^{\circ}$ and
} 


\section{INTRODUCTION}

The Brazilian health system presents peculiarities related to the way the public-private settlement results in health care. Hospital care is mainly carried out by private entities, which can simultaneously attended patients funded by the Brazilian Unified Health System (SUS) and by private health plans, producing complex financing settlements and assistance networks that make the regulation of the system difficult.

The interaction between SUS and health plans has been considered a factor that produces inequality in the access, use and, quality of health services ${ }^{22}$. In addition, the public-private competition for the same network of providers, without separation of the clientele served, raises problems in the organization of care and impairs the relationship of complementarity expected for the system².

Hospital mortality has been one of the most exploited indicators to measure hospital quality for representing an unequivocal result, a global measure of the care process, and also for its availability in the administrative databases ${ }^{5,6,19}$. Hospital mortality must be adjusted for the risk of the patients, to enable more reliable comparisons of providers. Traditionally, these adjustments include, in regression models, attributes of patients expressing degrees of risk of death ${ }^{6,13,16,23}$. In addition to the characteristics of the patients, the structure and functioning of hospitals may also affect hospital mortality. Therefore, the variation in hospital mortality can indicate problems in the quality of the care provided by hospitals. In this sense, to measure different explanatory factors involved is crucial in this approach, although it is not trivial.

In addition, complicating this type of analysis, there is the fact that patients in the same hospital have more similarity between themselves than with patients in different hospitals, generating dependency between observations within each hospital. To deal with this dependency, multilevel regression models have been used in some studies ${ }^{21}$.

The relationship between hospital mortality and structural and organizational characteristics of hospitals has received great attention in national and international literature ${ }^{4}$, with emphasis on the analysis of public or private nature ${ }^{2,8}$ and on source of financing for hospital admissions ${ }^{25,27}$. In Brazil, studies developed, in general, are restricted to certain geographical $\operatorname{areas}^{12,15}$. This is mainly due to the unavailability of secondary data with acceptable coverage and quality of fulfillment to the whole Brazilian territorya.

This study aimed to analyze if adjusted hospital mortality varies according to source of payment of hospital admissions, legal nature, and financing settlement of hospitals.

\section{METHODS}

\section{Study universe}

${ }^{a}$ Machado JP. O arranjo públicoprivado no Brasil e a qualidade da assistência hospitalar em São Paulo e no Rio Grande do Sul [these]. Rio de Janeiro (RJ): Escola Nacional de Saúde Pública, Fundação Oswaldo Cruz; 2014.

${ }^{\mathrm{b}}$ Department of Health and Human Services (UEA), Agency

for Healthcare Research and Quality. Guide to inpatient quality indicators: quality of care in hospitals: volume, mortality, and utilization. Version 3.1, Rockville, MD: Agency for Healthcare Research and Quality; 2007.
Were studied hospital admissions carried out between 2008 and 2010 in hospitals in Sao Paulo and Rio Grande do Sul, with better coverage and quality of fulfillment of Hospital Admissions Communication $(\mathrm{CIH})^{\mathrm{a}}$.

Of 39,419,539 hospital admissions recorded during this period, 7,385,323 were selected for patients aged between 18 and 99 years, admitted less than 30 days (acute), not transferred, in the specialties general surgery or internal medicine, whose procedures and diagnoses were unrelated to obstetrics, not occurring in hospitals with at least one hospital admission/day.

From these 7,385,323 hospital admissions, the study universe integrated the 852,864 regarding four causes with more admissions and deaths in Brazil, among the seven proposals for quality indicators for the Agency for Healthcare Research and Quality - AHRQ) ${ }^{b}$. They are: acute myocardial infarction - AMI (CID 21); congestive heart failure - CHF (CID I50, I11, I13); cerebrovascular accident - CVA (CID I60 I61 I62 CID, I63, I64); and pneumonia (CID J13, J14, J15, J16, J18). 
The use of these causes is based on greater causal validity of hospital mortality because of the care applied to such diagnoses, with evidences indicating relationship between process

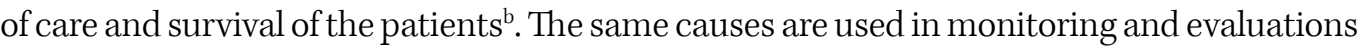
of quality in other countries, including comparisons between them ${ }^{5,19}$.

\section{Databases}

Were used administrative databases provided by the Department of Informatics of SUS (DATASUS) and by the National Health Agency (ANS), both linked to the Brazilian Ministry of Health.

For the SUS-financed admissions, data are from the System of Hospital Information of SUS (SIH/DATASUS); for the admissions whose source of payment were private or of health plan, data have as a source the CIH/DATASUS. For both cases are publicly available on the DATASUS website files with individualized data (however de-identified) of patients.

Data on the structure of public and private hospital network came from the National Registry of Health Establishments (CNES/DATASUS), also obtained in the website. Further data on private network have been obtained from the System of Health Plans Registry (RPS/ANS), upon request of information to the ANS.

\section{Analyses}

The dependent variable was the occurrence of in-hospital death. Data analysis was carried out in two steps: (1) risk adjustment model; (2) analysis of characteristics of the care process and the structure of hospitals.

The risk adjustment model included the following variables: sex, age, primary diagnosis, presence of comorbidity, Charlson Comorbidity Index (CCI), and clinical conditions of Elixhauser not covered by CCI. Several models were tested from the base model composed by age and sex, then including other variables. The variable type of admission (elective or emergency) has not been tested because it was not fulfilled in the CIH database. Although information about comorbidity are restricted in the sources of information used, the two comorbidity indexes have been used aiming to greater precision of risk adjustment models, qualifying them to represent a degree of information about comorbidity. The algorithm of Quan et al. ${ }^{16}$ was used in the construction of these indexes.

To assess the predictive ability of the models tested, the C-statistics (Receiver Operating Characteristics - ROC curve scores) was used. This test measures the probability predicted of risk of death in a randomly selected patient who died, compared to the probability of risk of death in a randomly selected patient who survived. For this statistics, the value of 0.5 suggests that the model is indifferent to a random chance of predicting death, while 1.0 suggests perfect discrimination; values up to 0.7 are considered of low discrimination, between 0.7 and 0.8 , of moderate discrimination, and above 0.8 , the model is considered predictive and of high discrimination ${ }^{1}$.

In the second step, variables regarding hospital admission level were: length of stay, type of procedure performed (surgical or clinical), use of Intensive Care Unit (ICU), and source of payment of hospital admission (SUS, health plan, or private). The variables regarding hospital level included were: legal nature, financing settlement, capacity, and educational activity.

As independent central variables in this study, it has been privileged: source of payment of the hospital admission, legal nature (public, for-profit private and non-profit private), and financing settlement (only SUS; SUS, health plans, and private; health plan and private) of the hospital.

The variable financing settlement is one of the types of institutional settlements, a term from the field of economics to describe forms of organization between market agents ${ }^{20}$. The financing settlement was built based on registration information and hospital production, 
each category indicating a combination in the sources of payment of admissions carried out in the hospital: "only SUS" refers to hospitals registered in the CNES with agreement only to SUS, not listed in the RPS, and no admissions in CIH; "SUS, health plans, and private" refers to those registered in the CNES with agreements with SUS, health plans, or private and included or not in the RPS, with admissions in SIH and CIH, or those registered in the CNES with agreement only with SUS, however included in the RPS or admissions in CIH; and "health plan and private" refers to those registered in the CNES with health plans or private agreements, included or not in the RPS, with no admissions in SIH.

\section{Multilevel Logistic Regression Model}

The multilevel logistic regression model with two levels (patient and hospital) used ${ }^{21}$ is expressed as follows:

$$
\operatorname{In}\left(\frac{p_{i j}}{1-p_{i j}}\right)=\beta^{\prime} x_{i j}+\gamma^{\prime} z_{j}+u_{0 j}
$$

Where: $p_{i j}$ is the probability of the ith patient of the jth hospital dying during admission; $\beta$ is the vector of parameters associated with the matrix of covariates of $x_{i j}$ patients; $\gamma$ is the vector of parameters associated with the variables of the hospital, that is, the second level of the multilevel model; $u_{0 j}$ is the random parameter that measures the variability of outcome between hospital units. It is assumed that $u_{0 j}$ has Normal distribution with zero mean and $\sigma_{o u}^{2}$ variance.

The parameters of multilevel models were estimated using MLwiN software, version 2.32. We used the Predictive near-likelihood procedure of second-order, considering the estimation process of MLwiN most suitable for multilevel models of binary response ${ }^{11}$. While standard deviation of the random effect can be directly estimated by the square root of the variance, the calculation of its standard error was obtained by Delta method ${ }^{7}$.

The effects of variables regarding patients and hospitals were interpreted in terms of ratio of chance and their respective 95\% confidence intervals. The residual effect of the hospitals was estimated at probabilities of death, calculated according to different levels of random effect: -2 standard deviations below mean, -1 standard deviation below mean, at mean, +1 standard deviation above mean, and +2 standard deviations above mean.

\section{RESULTS}

Of 852,864 hospital admissions selected, $41.0 \%$ were due to pneumonia, $30.0 \%$ to CHF, $19.0 \%$ to CVA, and $10.0 \%$ to AMI. The gross mortality rate was $13.5 \%$, with variations of $10.3 \%$ (CHF) and 17.3\% (CVA) between the selected causes (Table 1).

Most admissions were of patients between 60 and 79 years of age. The minority of them possessed some comorbidity, Charlson index other than zero, or presented some Elixhauser comorbidity. Most admissions were for up to seven days. Mostly, the ICU was not used and surgeries were not performed. The payment of hospital admissions was predominantly SUS. Admissions occurred mostly in private hospitals, without teaching activity, capacity greater than 49 beds, and mixed financing settlement: SUS, health plans, and private (Table 1). In hospitals with mixed settlement, admissions paid by SUS were majority. In hospitals of health plans and private settlement, admissions by health plans represented almost the total.

Regarding the risk adjustment model (Table 2), the better capacity of discrimination was from the model $10(\mathrm{C}$-statistics $=0.66)$, which incorporated sex, age group, CCI, Elixhauser comorbidities excluded from CCI, presence of comorbidity, and main diagnosis (Table 2). In the multilevel model (Table 3), higher chances of death were registered in admissions of male patients, in more advanced age groups, with comorbidity, with Charlson index greater than zero, who remained for one day at the hospital, used ICU, performed clinical procedure, 
Table 1. Characteristics of the study population. Sao Paulo and Rio Grande do Sul, Brazil, 2008-2010.

\begin{tabular}{|c|c|c|c|c|}
\hline \multirow{2}{*}{ Characteristic } & \multicolumn{2}{|c|}{ Hospital admissions } & \multicolumn{2}{|c|}{ Deaths } \\
\hline & $\mathbf{n}$ & $\%$ & $\mathbf{n}$ & $\%$ \\
\hline Total & 852,864 & 100.0 & 115,347 & 13.5 \\
\hline \multicolumn{5}{|l|}{ State of admission } \\
\hline Sao Paulo & 628,596 & 73.7 & 91,113 & 14.5 \\
\hline Rio Grande do Sul & 224,268 & 26.3 & 24,234 & 10.8 \\
\hline \multicolumn{5}{|l|}{ Sex } \\
\hline Male & 438,443 & 51.4 & 58,719 & 13.4 \\
\hline Female & 414,421 & 48.6 & 56,628 & 13.7 \\
\hline \multicolumn{5}{|l|}{ Age group } \\
\hline $0-49$ years & 161,295 & 18.9 & 11,239 & 7.0 \\
\hline 50-59 years & 133,965 & 15.7 & 13,679 & 10.2 \\
\hline 60-69 years & 167,902 & 19.7 & 20,473 & 12.2 \\
\hline 70-79 years & 202,047 & 23.7 & 30,474 & 15.1 \\
\hline 80-89 years & 152,145 & 17.8 & 29,973 & 19.7 \\
\hline $90-99$ years & 35,510 & 4.2 & 9,509 & 26.8 \\
\hline \multicolumn{5}{|l|}{ Main diagnosis } \\
\hline AMI (I21 Acute myocardial infarction) & 85,526 & 10.0 & 12,382 & 14.5 \\
\hline $\mathrm{CHF}$ & 253,724 & 29.7 & 26,254 & 10.3 \\
\hline I11 Hypertensive heart disease & 12,236 & 1.4 & 232 & 1.9 \\
\hline I13 Hypertensive heart and renal disease & 763 & 0.1 & 29 & 3.8 \\
\hline I50 Heart failure & 240,725 & 28.2 & 25,993 & 10.8 \\
\hline CVA & 159,947 & 18.8 & 27,708 & 17.3 \\
\hline I60 Subarachnoid hemorrhage & 9,171 & 1.1 & 1,956 & 21.3 \\
\hline I61 Intracerebral hemorrhage & 15,715 & 1.8 & 4,463 & 28.4 \\
\hline I62 Other nontraumatic intracranial hemorrhage & 5,649 & 0.7 & 1,307 & 23.1 \\
\hline 163 Cerebral infarction & 23,286 & 2.7 & 3,211 & 13.8 \\
\hline $\begin{array}{l}164 \text { Cerebrovascular accident, unspecified as } \\
\text { hemorrhagic or ischemic }\end{array}$ & 106,126 & 12.4 & 16,771 & 15.8 \\
\hline Pneumonia & 353,667 & 41.5 & 49,003 & 13.9 \\
\hline J13 Pneumonia due to Streptococcus pneumoniae & 662 & 0.1 & 66 & 10.0 \\
\hline J14 Pneumonia due to Haemophilus infuenzae & 196 & 0.0 & 21 & 10.7 \\
\hline J15 Bacterial pneumonia not classified elsewhere & 49,540 & 5.8 & 7,097 & 14.3 \\
\hline $\begin{array}{l}\text { J16 Pneumonia due to other specified infectious } \\
\text { microorganisms not classified elsewhere }\end{array}$ & 3,155 & 0.4 & 358 & 11.3 \\
\hline J18 Pneumonia by unspecified microorganism & 300,114 & 35.2 & 41,461 & 13.8 \\
\hline \multicolumn{5}{|l|}{ Comorbidity registered } \\
\hline No & 725,800 & 85.1 & 91,665 & 12.6 \\
\hline Yes & 127,064 & 14.9 & 23,682 & 18.6 \\
\hline \multicolumn{5}{|l|}{ Charlson Comorbidity Index } \\
\hline 0 & 822,331 & 96.4 & 109,166 & 13.3 \\
\hline 1 & 23,304 & 2.7 & 4,062 & 17.4 \\
\hline 2 & 7,229 & 0.8 & 2,119 & 29.3 \\
\hline \multicolumn{5}{|l|}{ Elixhauser Comorbidity Index } \\
\hline 0 & 785,586 & 92.1 & 104,953 & 13.4 \\
\hline 1 & 67,278 & 7.9 & 10,394 & 15.4 \\
\hline \multicolumn{5}{|l|}{ Use of intensive care unit. } \\
\hline No & 735,324 & 86.2 & 80,626 & 11.0 \\
\hline Yes & 117,540 & 13.8 & 34,721 & 29.5 \\
\hline
\end{tabular}

Continua 
Table 1. Characteristics of the study population. Sao Paulo and Rio Grande do Sul, Brazil, 2008-2010. Continuation

\begin{tabular}{|c|c|c|c|c|}
\hline \multicolumn{5}{|l|}{ Type of procedure } \\
\hline Clinical & 813,660 & 95.4 & 110,010 & 13.5 \\
\hline Surgical & 39,204 & 4.6 & 5,337 & 13.6 \\
\hline \multicolumn{5}{|l|}{ Length of stay } \\
\hline Up to 1 day & 66,217 & 7.8 & 25,349 & 38.3 \\
\hline From 2 to 7 days & 540,761 & 63.4 & 51,566 & 9.5 \\
\hline From 8 to 14 days & 169,913 & 19.9 & 22,964 & 13.5 \\
\hline From 15 to 21 days & 51,349 & 6.0 & 9,772 & 19.0 \\
\hline From 22 to 30 days & 24,624 & 2.9 & 5,696 & 23.1 \\
\hline \multicolumn{5}{|l|}{ Payment of hospital admission } \\
\hline SUS & 645,606 & 75.7 & 94,146 & 14.6 \\
\hline Health plan & 178,211 & 20.9 & 17,997 & 10.1 \\
\hline Private & 18,706 & 2.2 & 1,923 & 10.3 \\
\hline Philanthropy & 10,341 & 1.2 & 1,281 & 12.4 \\
\hline \multicolumn{5}{|l|}{ Hospital quality } \\
\hline Public & 241,702 & 28.3 & 41,914 & 17.3 \\
\hline Non-profit private & 507,938 & 59.6 & 61,831 & 12.2 \\
\hline For-profit private & 103,224 & 12.1 & 11,602 & 11.2 \\
\hline \multicolumn{5}{|l|}{ Teaching activity at the hospital } \\
\hline No & 624,546 & 73.2 & 82,022 & 13.1 \\
\hline Yes & 228,318 & 26.8 & 33,325 & 14.6 \\
\hline \multicolumn{5}{|l|}{ Hospital financing settlement } \\
\hline Only SUS & 119,815 & 14.0 & 21,741 & 18.1 \\
\hline SUS, health plans, and private & 637,007 & 74.7 & 82,989 & 13.0 \\
\hline Health plans and private & 96,042 & 11.3 & 10,617 & 11.1 \\
\hline \multicolumn{5}{|l|}{ Capacity of the hospital } \\
\hline Up to 49 beds & 81,743 & 9.6 & 8,040 & 9.8 \\
\hline From 50 to 149 beds & 297,474 & 34.9 & 37,815 & 12.7 \\
\hline From 150 to 299 beds & 304,808 & 35.7 & 45,894 & 15.1 \\
\hline 300 beds or more & 168,839 & 19.8 & 23,598 & 14.0 \\
\hline
\end{tabular}

AMI: acute myocardial infarction; CHF: congestive heart failure; CVA: cerebrovascular accident; SUS: Brazilian Unified Health System

and with SUS as source of payment. At the level of hospitals, only the variable capacity proved to be statistically significant, with higher chance of death among larger hospitals (Table 3).

The random effect, regarding the inter-hospital variation unexplained by the variables included in the model, was statistically significant, indicating that the chance of death of patients admitted to hospitals within one standard deviation above the mean e was $98.0 \%$ higher than that of patients admitted to hospitals on mean distribution. The Figure shows the probabilities of death for the categories of the variable source of payment according to random effect levels, that depict the variability in mortality between hospitals. Between hospitals within the mean, the greater probability of death was observed in patients with admissions paid by SUS, almost twice of those with health plan or private sources of payment. The probability of death increased significantly among patients admitted to hospitals within two standard deviations above the mean. In the case of patients with hospital admission paid by SUS, the probability of death reached $29.0 \%$. Although admissions financed by health plan or private report less probability to death, this relationship can be changed depending on the hospital in which the patient was admitted to: admissions with health plan as source of payment, if occurred in hospitals within two standard deviations above the mean, had almost twice the probability of admissions whose source of payment was SUS, when admitted to hospitals within the mean (Figure). 
Table 2. Risk adjustment models tested. Sao Paulo and Rio Grande do Sul, Brazil, 2008-2010.

\begin{tabular}{|c|c|c|c|}
\hline Model & & & C-statistics \\
\hline \multirow{8}{*}{ Simple models } & 1 & Base model (age and sex) & 0.62 \\
\hline & 2 & Base model + comorbidity & 0.63 \\
\hline & 3 & Base model $+\mathrm{CCl}$ & 0.62 \\
\hline & 4 & Base model + Elixhauser index & 0.62 \\
\hline & 5 & Base model + Elixhauser components ${ }^{\mathrm{a}}$ & 0.62 \\
\hline & 6 & Base model $+\mathrm{CCl}$ of main diagnosis & 0.62 \\
\hline & 7 & Base model + main diagnosis & 0.65 \\
\hline & 8 & Base model + main diagnosis group & 0.64 \\
\hline \multirow{6}{*}{$\begin{array}{l}\text { Risk adjustment } \\
\text { models } \\
\text { composed }\end{array}$} & 5 & Base model $+\mathrm{CCl}+$ comorbidity & 0.63 \\
\hline & 6 & Base model $+\mathrm{CCl}+$ Elixhauser index & 0.62 \\
\hline & 7 & Base model $+\mathrm{CCl}+$ Elixhauser components ${ }^{\mathrm{a}}$ & 0.62 \\
\hline & 9 & Base model $+\mathrm{CCl}+$ Elixhauser components ${ }^{\mathrm{a}}+$ comorbidity & 0.63 \\
\hline & $10^{\mathrm{b}}$ & $\begin{array}{c}\text { Base model }+\mathrm{CCl}+\begin{array}{l}\text { Elixhauser components } \\
\text { main diagnosis }\end{array} \\
\text { mamorbidity }+\end{array}$ & 0.66 \\
\hline & 11 & $\begin{array}{c}\text { Base model }+\mathrm{CCl}+\text { Elixhauser components }{ }^{\mathrm{a}}+\text { comorbidity }+^{\text {main diagnosis group }}\end{array}$ & 0.65 \\
\hline
\end{tabular}

Source: Brazilian Ministry of Health. National Register of Health Establishments (CNES), Health Plans Registry (RPS), System of Hospital Information of SUS (SIH), and Hospital Admissions Communication $(\mathrm{ClH})$.

CCl: Charlson Comorbidity Index

a Includes other than those referred to in the Charlson Index, significant and with risk effect.

${ }^{\mathrm{b}}$ Final risk adjustment model.

Table 3. Multilevel logistic regression model of hospital mortality: ratio of chances of death and estimated confidence intervals. Sao Paulo and Rio Grande do Sul, Brazil, 2008-2010.

\begin{tabular}{|c|c|c|c|c|}
\hline Variable & Coefficient & $\begin{array}{c}\text { Standard } \\
\text { error }\end{array}$ & $\begin{array}{l}\text { Ratio of } \\
\text { chance }\end{array}$ & $95 \% \mathrm{Cl}$ \\
\hline Constant & -3.530 & 0.117 & - & - \\
\hline \multicolumn{5}{|c|}{ First level: patients } \\
\hline \multicolumn{5}{|l|}{ Patient characteristics and risk adjustment } \\
\hline \multicolumn{5}{|l|}{ Sex (ref. cat.: male) } \\
\hline Female & -0.046 & 0.007 & 0.955 & $0.942-0.968$ \\
\hline \multicolumn{5}{|l|}{ Age group (ref. cat.: $<50$ years) } \\
\hline $50-59$ years & 0.480 & 0.015 & 1.616 & $1.569-1.664$ \\
\hline $60-69$ years & 0.775 & 0.014 & 2.171 & $2.112-2.231$ \\
\hline 70-79 years & 1.141 & 0.013 & 3.130 & $3.051-3.211$ \\
\hline 80-89 years & 1.585 & 0.013 & 4.879 & $4.757-5.005$ \\
\hline 90-99 years & 2.072 & 0.018 & 7.941 & $7.665-8.226$ \\
\hline \multicolumn{5}{|c|}{ Presence of comorbidity (ref. cat.: no comorbidity) } \\
\hline With Comorbidity & 0.901 & 0.016 & 2.462 & $2.386-2.540$ \\
\hline \multicolumn{5}{|l|}{ Charlson Comorbidity Index (ref. cat.: $\mathrm{CCl}=0$ ) } \\
\hline $\mathrm{CCl}=1$ & 0.211 & 0.022 & 1.235 & $1.183-1.289$ \\
\hline $\mathrm{CCl} \geq 2$ & 0.726 & 0.032 & 2.067 & $1.941-2.201$ \\
\hline \multicolumn{5}{|c|}{ Elixhauser components (ref. cat.: no specific comorbidity) } \\
\hline Cardiac arrhythmia & 0.917 & 0.113 & 2.502 & $2.005-3.122$ \\
\hline Pulmonary circulation disease & 0.776 & 0.269 & 2.173 & $1.282-3.681$ \\
\hline Other neurological disease & 0.027 & 0.103 & 1.027 & $0.840-1.257$ \\
\hline Coagulopathies & 0.333 & 0.147 & 1.395 & $1.046-1.861$ \\
\hline Weight loss & 0.290 & 0.107 & 1.336 & $1.084-1.648$ \\
\hline Hydroelectrolytic imbalance & 0.144 & 0.058 & 0.866 & $0.773-0.970$ \\
\hline Alcohol abuse & -0.300 & 0.093 & 0.741 & $0.617-0.889$ \\
\hline \multicolumn{5}{|c|}{ Main diagnosis (ref. cat.: I11 hypertensive heart disease) } \\
\hline 113 Hypertensive heart and renal disease & 0.590 & 0.212 & 1.804 & $1.191-2.733$ \\
\hline
\end{tabular}


Table 3. Multilevel logistic regression model of hospital mortality: ratio of chances of death and estimated confidence intervals. Sao Paulo and Rio Grande do Sul, Brazil, 2008-2010. Continuation

\begin{tabular}{|c|c|c|c|c|}
\hline I21 Acute myocardial infarction & 1.718 & 0.073 & 5.573 & $4.830-6.431$ \\
\hline I50 Heart failure & 1.848 & 0.073 & 6.347 & $5.501-7.323$ \\
\hline I60 Subarachnoid hemorrhage & 2.763 & 0.078 & 15.847 & $13.601-18.465$ \\
\hline I61 Intracerebral hemorrhage & 3.053 & 0.075 & 21.179 & $18.284-24.533$ \\
\hline I62 Other nontraumatic intracranial hemorrhage & 2.877 & 0.081 & 17.761 & $15.154-20.817$ \\
\hline I63 Cerebral infarction & 2.088 & 0.076 & 8.069 & $6.952-9.365$ \\
\hline I64 Cerebrovascular accident, unspecified as hemorrhagic or ischemic & 2.288 & 0.073 & 9.855 & $8.541-11.371$ \\
\hline J13 Pneumonia due to Streptococcus pneumoniae & 2.139 & 0.161 & 8.491 & $6.193-11.641$ \\
\hline J14 Pneumonia due to Haemophilus infuenzae & 2.391 & 0.279 & 10.924 & $6.323-18.875$ \\
\hline J15 Bacterial pneumonia not classified elsewhere & 2.499 & 0.074 & 12.170 & $10.527-14.070$ \\
\hline $\begin{array}{l}\text { J16 Pneumonia due to other specified infectious microorganisms not } \\
\text { classified elsewhere }\end{array}$ & 2.180 & 0.099 & 8.846 & $7.286-10.741$ \\
\hline J18 Pneumonia by unspecified microorganism & 2.454 & 0.072 & 11.635 & $10.103-13.398$ \\
\hline \multicolumn{5}{|l|}{$\begin{array}{l}\text { laracteristics of the care process and source of payment } \\
\text { Length of stay (ref. cat.: } 1 \text { day) }\end{array}$} \\
\hline $2-7$ days & -2.152 & 0.011 & 0.116 & $0.114-0.119$ \\
\hline 8-14 days & -2.112 & 0.013 & 0.121 & $0.118-0.124$ \\
\hline 15-21 days & 1.893 & 0.016 & 0.151 & $0.146-0.155$ \\
\hline 22-30 days & -1.754 & 0.020 & 0.173 & $0.166-0.180$ \\
\hline Use of ICU during hospital admission (ref. cat.: no use) & 1.804 & 0.010 & 6.074 & $5.956-6.194$ \\
\hline Type of procedure performed (ref. cat.: clinical) & -0.696 & 0.020 & 0.499 & $0.479-0.519$ \\
\hline \multicolumn{5}{|l|}{ Source of payment of admission (ref. cat.: SUS) } \\
\hline Health plan & -0.740 & 0.016 & 0.477 & $0.462-0.492$ \\
\hline Private & -0.777 & 0.030 & 0.460 & $0.434-0.488$ \\
\hline Philanthropy & -0.382 & 0.037 & 0.682 & $0.635-0.734$ \\
\hline \multicolumn{5}{|c|}{ Second level: hospitals } \\
\hline \multicolumn{5}{|l|}{ Legal nature (ref. cat.: public) } \\
\hline Non-profit private & -0.255 & 0.137 & 0.775 & $0.592-1.014$ \\
\hline For-profit private & -0.163 & 0.089 & 0.850 & $0.714-1.012$ \\
\hline \multicolumn{5}{|l|}{ Financing settlement (ref. cat.: only SUS) } \\
\hline Health plans and private & -0.291 & 0.158 & 0.748 & $0.548-1.019$ \\
\hline SUS, health plans, and private & -0.214 & 0.109 & 0.807 & $0.652-1.000$ \\
\hline \multicolumn{5}{|l|}{ Capacity (ref. cat.: < 50 beds) } \\
\hline $50-149$ beds & 0.331 & 0.065 & 1.392 & $1.226-1.582$ \\
\hline $150-299$ beds & 0.277 & 0.080 & 1.319 & $1.128-1.543$ \\
\hline 300 beds or more & 0.373 & 0.127 & 1.452 & $1.132-1.863$ \\
\hline \multicolumn{5}{|l|}{ Teaching activity (ref. cat.: no teaching is performed) } \\
\hline Teaching activity is performed & -0.080 & 0.088 & 0.923 & $0.777-1.097$ \\
\hline \multicolumn{5}{|l|}{ Random effect } \\
\hline$\sigma \mathrm{u}$ & 0.685 & 0.006 & 1.984 & $1.960-2.007$ \\
\hline
\end{tabular}

ref. cat.: reference category; CCI: Charlson Comorbidity Index; ICU: intensive care unit; SUS: Brazilian Unified Health System

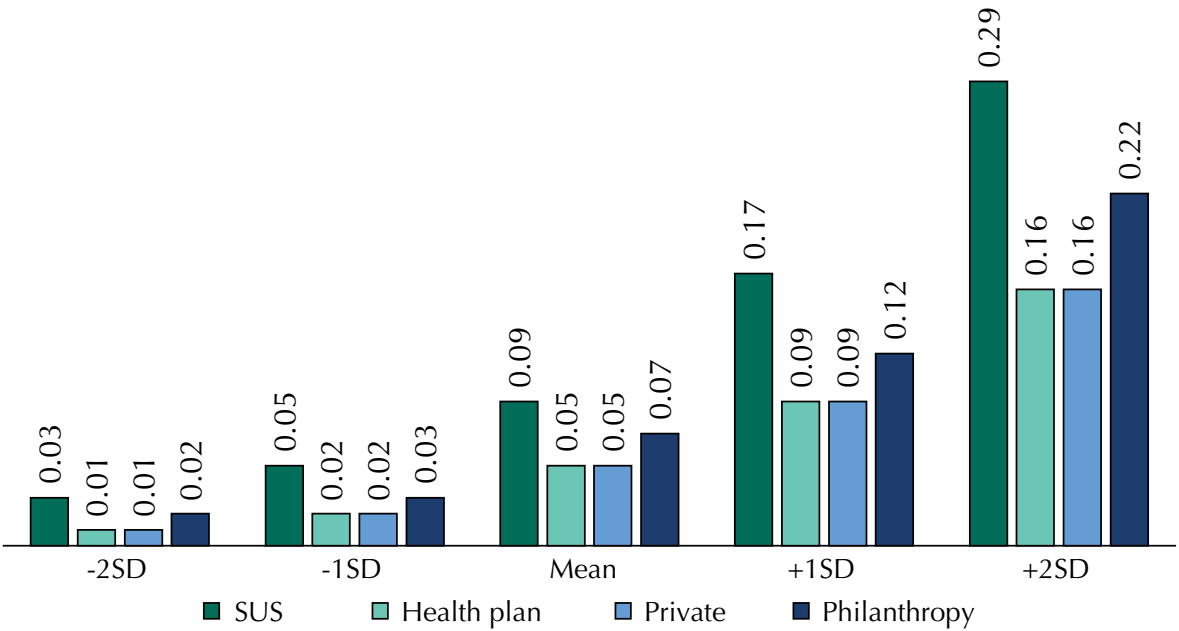

SD: standard deviation; SUS: Brazilian Unified Health System

Figure. Probability of death per source of payment of hospital admission, according to values of random effects estimated in the multilevel model. Sao Paulo and Rio Grande do Sul, Brazil, 2008-2010. 


\section{DISCUSSION}

In Brazil, few studies analyze the quality of hospital care measured by risk-adjusted mortality employing multilevel models. Yet, the results found align to those of national studies identified $^{16,20}$. At the international level, if on one hand the selection of four of the seven groups of causes recommended by AHRQ brings the need for adaptations for comparison between publications with similar approaches, on the other hand, there is variability in the set of selected code in European studies, corroborating the need of local adaptations as the one carried out ${ }^{5,19}$.

Regarding risk adjustment, the variables here used have similarities with those used in international and national studies, for their recognized relationship with the risk of death and availability in databases ${ }^{1,6,12,23,25,27}$. On the other hand, in relation to information about comorbidity and related indexes, although less used in Brazilian studies because of the incompleteness of the records ${ }^{16}$, they were included in this study aiming at improving the predictive ability of risk adjustment model and, above all, the conceptual coherence with the analytical approach.

The treatment applied to length of stay and some of the results were similar to those studies that use global approach of hospital mortality ${ }^{14,17}$. The high risk of death observed on the first day of admission is possibly related to emergency cases, especially those requiring palliative care or with lower therapeutic possibilities ${ }^{17}$. On the other hand, the global approach of hospital mortality uses the length of stay as adjustment variable ${ }^{14}$, option here excluded, since the length of stay may express greater gravity, adverse events resulting from problems in the quality of care or availability of beds for long term care ${ }^{15}$.

Regarding the association between hospital mortality and hospital characteristics, we expected to find a lower risk of death in larger hospitals, for their better structure and for the relationship between volume and quality described in literature ${ }^{3}$. However, the analysis showed a higher risk in larger hospitals, similar to what Garcia et al..$^{12}$ observed. In addition, the gradient of risk of death was similar between capacity classes, differentiating only hospitals with capacity smaller or greater than 50 beds. Despite the minimum cut of hospital volume in one case a day, smaller hospitals seem to present specific role with some degree of experience in hospital care of the causes studied, factor that may contribute to the better outcome of care.

The analysis showed the effect of the source of payment on the risk of death. Patients with private health plan or that pay out their own pocket (private) showed lower adjusted mortality rates than patients of SUS, although admitted to the same hospitals. Similar results were published in international studies, mainly from the USA, where the benefits are of patients covered by private insurances, when compared with those covered by public insurances ${ }^{25,27}$. In Brazil, Martins et al. ${ }^{15}$ also found higher risk of death among patients of SUS, however, they did not studied possible sources of payment disparities within the same hospitals, here explored by the analysis of financing settlements.

Studies conducted in the United States showed higher risk of death among uninsured patients and with private payment ${ }^{8,25}$. This difference may be related to different eligibility of patients to public health services in both countries. In Brazil, the entire population is eligible to SUS; in the USA, some people are ineligible for public insurance and also do not have private insurance. Thus, while private patients in the USA are mostly excluded from both modalities (public and private), in Brazil patients who pay private hospitalization tend to have higher purchasing power or are beneficiaries of the best health plans, with good margins of reimbursement.

Of the factors that contribute to disparities in the risk of death among sources of payment we highlight the differences between clinical practice, access to technology, and procedures of high cost and complexity ${ }^{8}$. Analyzing the Brazilian health system, Victora et al. ${ }^{26}$ suggests that service providers that attend SUS patients and non-SUS patients offer differentiated 
standard of care according to the values they receive, which would influence the choice of procedure and material used, thus affecting quality of care and possibly the risk of death or occurrence of other adverse results.

Although there were privileged variables in this study, the effect of the financing settlement and legal nature of the hospital on the adjusted mortality showed no significance. However, although this feature had not been able to differentiate the risk of death in hospitals, we observe, within the same physical structures, differences between patients with source of payment SUS and non-SUS. This suggests that even physically available in hospitals, some resources are not available to patients of SUS, indicating iniquities in the process of hospital care.

Some limitations are inherent to the use of administrative databases, often designed originally to billing services. Therefore, their content may not comprise the whole set of information necessary for analyses of quality of services, or there may be incomplete or incorrect data collection, affecting the analyses developed. Nevertheless, the use of such data is an alternative explored in many countries due to the ease of obtaining, comprehensiveness, and continuity ${ }^{15, a}$. This study highlights the use of $\mathrm{CIH}$, which, despite representing the only source about non-SUS admissions in the country, is little used in Brazilian studies, often due to its questionable quality. Considering the variables of interest and the need to use the $\mathrm{CIH}$ to the proposed analyses, we opted for the delimitation of the study universe in two states with best coverage, in which we also observed reasonable degree of consistency in the data, according to a study of Machadoa.

Incompleteness of data on the severity profile of patients in Brazilian information systems, both public and private, outstands as another limitation. Incompleteness has been discussed in evaluation studies, since it prevents more accurate risk adjustments, compromising the accuracy of the analysis. In this sense, higher risk of death in public hospitals observed in this study may reflect failures in risk adjustment for not precisely measuring the greater severity of patients who use public services, possibly those with the worst socioeconomic conditions. However, the use of the source of payment as indicative of the health condition of the patient at the time of admission would not be an appropriate solution, since it would exclude from the analysis problems in the quality of care provided associated with discrimination or inequity. A specific restraint was the noninclusion of the risk model of the type of admission (elective or emergency), due to its nonfulfillment at the base of $\mathrm{CIH}$, since national studies found relationship with the chance of death ${ }^{12,20}$.

The restricted degree of some categorical variables brought difficulties and also represents a limitation in the analyses. Especially in the case of financing settlements, each of the three categories studied includes groups of hospitals with varied proportion of sources of payment of admissions that compose its clientele. Are distinct hospitals that attend $20.0 \%$ or $80.0 \%$ of the patients by SUS, and this difference possibly influenced in varying degrees the result of the care, especially considering that sources of showed significant effect on the risk of death.

Although presenting limits that point to the need for improvement and expansion of clinical information registered in databases, the approach used in this study to assess hospital mortality, with the application of risk adjustment, multilevel regression risk, and use of administrative data, allowed more accurate estimation of the effect of the characteristics of admissions and hospitals on the risk of death. Even after controlling the effects of individual risk and considering the hierarchy between the levels of analysis, the findings of this study indicate the existence of differences in the quality of hospital care, measured by adjusted mortality, according to sources of payment of the hospital admission. This analysis indicated a disadvantage for SUS patients when compared with patients of health plans or with private payment, including when admitted to the same hospital. In addition to structural characteristics of the hospitals and the profile of the patients, the elaboration of policies aimed at this area should also consider the coverage of the population by health plans, the network shared between beneficiaries of plans and users of SUS, the dynamics of attendance 
to the various sources of payment by hospitals and, most importantly, how these factors influence the clinical performance. Therefore, they would contribute to the reduction of inequalities and to improve the effectiveness of the health system.

\section{REFERENCES}

1. Aylin P, Bottle A, Majeed A. Use of administrative data or clinical databases as predictors of risk of death in hospital: comparison of models. BMJ Online. 2007;334:1044. DOI:10.1136/bmj.39168.496366.55

2. Basu S, Andrews J, Kishore S, Panjabi R, Stuckler D. Comparative performance of private and public healthcare systems in low and middle-income countries: a systematic review. PLoS Med. 2012;9(6):E100124. DOI:10.1371/journal.pmed.1001244

3. Birkmeyer JD, Dimick JB, Staiger DO. Operative mortality and procedure volume as predictors of subsequent hospital performance. Ann Surg. 2006;243(3):411-7. DOI:10.1097/01.sla.0000201800.45264.51

4. Brand CA, Barker AL, Morello RT, Vitale MR, Evans SM, Scott IA et al. A review of hospital characteristics associated with improved performance. Int I Qual Health Care. 2012;24(5):483-94. DOI:10.1093/intqhc/mzs044

5. Burnett S, Renz A, Wiig S, Fernandes A, Weggelaar AM, Calltorp J et al. Prospects for comparing European hospitals in terms of quality and safety: lessons from a comparative study in five countries. Int I Qual Health Care. 2013;25(1):1-7. DOI:10.1093/intqhc/mzs079

6. Campbell MJ, Jacques RM, Fotheringham J, Maheswaran R, Nicholl J. Developing a summary hospital mortality index: retrospective analysis in English hospitals over five years. BMJ. 2012;344:e1001. DOI:10.1136/bmj.e1001

7. Casella GE, Berger RL. Statistical inference. 2nd ed. Pacific Grove: Duxbury; 2002.

8. Eggleston K, Shen YC, Lau J, Schmid CH, Chan J. Hospital ownership and quality of care: what explains the different results in the literature? Health Econ. 2008;17(12):1345-62. DOI:10.1002/hec.1333

9. Fung V, Schmittdiel JA, Fireman B, Meer A, Thomas S, Smider $\mathrm{N}$ et al. Meaningful variation in performance: a systematic literature review. Med Care. 2010;48(2):140-8. DOI:10.1097/MLR.0b013e3181bd4dc3

10. Gala P. A teoria institucional de Douglass North. Rev Econ Polit. 2003;23(2):89-105.

11. Goldstein H, Rasbash J. Improved approximations for multilevel models with binary responses. JR Stat Soc. 1996;59(3):505-13. DOI:10.2307/2983328

12. Gomes AS, Klück MM, Fachel JMG, Riboldi J. Fatores associados à mortalidade hospitalar na rede SUS do Rio Grande do Sul, em 2005: aplicação de modelo multinível. Rev Bras Epidemiol. 2010;13(3):533-42. DOI:10.1590/S1415-790X2010000300016

13. lezzoni LI. Risk adjustment for performance measurement. In: Smith PC, Mossialos E, Papanicolas I, Leatherman S. Performance measurement for health system improvement: experiences, challenges and prospects. Cambridge: Cambridge University Press; 2009. p. 251-368.

14. Jarman B, Pieter D, Veen AA, Kool RB, Aylin P, Bottle A et al. The hospital standardised mortality ratio: a powerful tool for Dutch hospitals to assess their quality of care? Qual Saf Health Care. 2010;(19):9-13. DOI:10.1136/qshc.2009.032953

15. Martins M, Blais R, Leite IC. Mortalidade hospitalar e tempo de permanência: comparação entre hospitais públicos e privados na região de Ribeirão Preto, São Paulo, Brasil. Cad Saude Publica. 2004;20 Suppl 2:S268-82. DOI:10.1590/S0102-311X2004000800021

16. Martins M. Uso de medidas de comorbidades para predição de risco de óbito em pacientes brasileiros hospitalizados. Rev Saude Publica. 2010;44(3):448-56 . DOI:10.1590/S0034-89102010005000003

17. Mohammed MA, Deeks JJ, Girling A, Rudge G, Carmalt M, Stevens AJ et al. Evidence of methodological bias in hospital standardised mortality ratios: retrospective database study of English hospitals. BMJ. 2009;338:b780. DOI:10.1136/bmj.b780

18. Noronha JC. Cobertura universal de saúde: como misturar conceitos, confundir objetivos, abandonar princípios. Cad Saude Publica. 2013;29(5):847-9. 
19. Pitches DW, Mohammed MA, Lilford RJ. What is the empirical evidence that hospitals with higher-risk adjusted mortality rates provide poorer quality care? A systematic review of the literature. BMC Health Serv Res. 2007;7(1):91. DOI:10.1186/1472-6963-7-91

20. Rolim CLRC, Martins M. Qualidade do cuidado ao acidente vascular cerebral isquêmico no SUS. Cad Saude Publica. 2011;27(11):2106-16. DOI:10.1590/S0102-311X2011001100004

21. Sanagou M, Wolfe R, Forbes A, Reid CM. Hospital-level associations with 30-day patient mortality after cardiac surgery: a tutorial on the application and interpretation of marginal and multilevel logistic regression. BMC Med Res Methodol. 2012;12(1):28. DOI:10.1186/1471-2288-12-28

22. Santos IS. Evidência sobre o mix público-privado em países com cobertura duplicada: agravamento das iniquidades e da segmentação em sistemas nacionais de saúde. Cienc Saude Coletiva. 2011;16(6):2743-52. DOI:10.1590/S1413-81232011000600013

23. Sharabiani MTA, Aylin P, Bottle A. Systematic review of comorbidity indices for administrative data. Med Care. 2012;50(12):1109-18. DOI:10.1097/MLR.0b013e31825f64d0

24. Snijders TAB. Multilevel analysis. In:Lovric M, editor. International encyclopedia of statistical science. Berlin: Springer; 2011. p. 87-82.

25. Spencer CS, Gaskin DJ, Roberts ET. The quality of care delivered to patients within the same hospital varies by insurance type. Health Aff (Millwoood). 2013;32(10):1731-9. DOI:10.1377/hlthaff.2012.1400

26. Victora CG, Barreto ML, Leal MC, Monteiro CA, Schmidt MI, Paim J et al Health conditions and health-policy innovations in Brazil: the way forward. Lancet. 2011;377(9792):2042-53. DOI:10.1016/S0140-6736(11)60055-X

27. Weissman JS, Vogeli C, Levy DE. The quality of hospital care for Medicaid and private pay patients. Med Care. 2013;51(5):389-95. DOI:10.1097/MLR.0b013e31827fef95

Authors' Contribution: JPM participated in all stages of development of the study and in the elaboration of this article. ICL and MM participated in the elaboration, data analysis, writing, and critical review.

Conflict of Interest: The authors declare no conflict of interest. 